2 Kantchev KN, Tcholakov BN, Casey R, Lehman H, El Hazm $M$. Twelve families with $\mathrm{Hb} O \mathrm{Arab}$ in the Burgas district of Bulgaria. Observations on sixteen examples of Hb O-Arab- $\beta$ thalassaemia. Humangenetik 1975;26:93-7.

3 Efremov GD, Sadikario A, Stojankov A, Dejcinov D, Huisman THJ. Homozygous hemoglobin O-Arab in a gypsy family in Yugoslavia. Hemoglobin 1977; 1 (4):389-94.

4 Altay C, Gurgey A, Huisman THJ. Homozygosity for haemo-

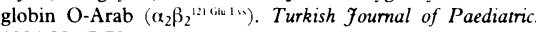
1986;28:67-72

5 Ben Abdeladhim A, Assioui B, Boussen M. Hemoglobinopathie O-Arab homozygote dans une famille tunisienne. Tunise Medicale 1987;65:571-4.

6 Heard SE, Westwood NB, Pearson TC, Stephens AD. Homozygous haemoglobin O-Arab in pregnancy. Clin Lab Haemalol 1991;13:319-20.

7 Rachmilewitz EA, Tamari H, Liff F, Yashiero U, Nagel RL. The interaction of haemoglobin $\mathrm{O}-\mathrm{Arab}$ with $\mathrm{HbS}$ and $\beta$ thalassaemia among Israeli Arabs. Hum Genet 1985;70:119-2

\section{Social and functional impact of minor fractures in elderly people}

SIR, - The findings of J M Nankhonya and colleagues on the social and functional impact of minor fractures in elderly people will not surprise those working in accident and emergency medicine.

A six month study in the accident and emergency department of Charing Cross Hospital showed that 55 of 66 patients $(83 \%)$ aged over 75 who attended with minor fractures of the ankle, wrist, or humerus could safely be discharged within two hours, during the normal working day of 9 am to $5 \mathrm{pm}$, if a prospective nursing and social assessment was made by a senior nurse before discharge. The nurse could then liaise with local social services and voluntary organisations to ensure that support was increased from the time the patient returned home. During a control period when no such assessment was made only 25 of 57 patients $(44 \%)$ with similar fractures could be safely discharged.

Obviously some patients present outside the normal working day, when it is not possible to arrange increased social support. In these circumstances an accident and emergency ward is invaluable in providing temporary care until these patients can be fully assessed and the appropriate services arranged the next day. In our experience, patients rarely need to stay more than 24 hours after their injury while this support is arranged.

A careful social and nursing assessment of elderly people who present with minor fractures is as important as the management of their injury itself. By assessing their needs while they are in the accident and emergency department and coordinating the response of community services it should be possible to ensure the safe discharge of such patients from hospital while at the same time avoiding their inappropriate admission to hospital.

MADELEINE WILLIAN MICHAEL LAMBERT HUGH MILLINGTON

Accident and Emergency Department,

Charing Cross Hospital,

London W6 8RF

Department of Care of the Elderly,

BRIAN LIVESLEY Charing Cross Hospita

1 Nankhonya JM, Turnbull CJ, Newton JT. Social and functional impact of minor fractures in elderly people. BMF 1991;303: 1514-5. (14 December.)

\section{Intensified conventional insulin treatment and neuropsychological impairment}

SIR,-Per Reichard and colleagues conclude that episodes of serious hypoglycaemia did not cause permanent cognitive impairment in diabetic patients in their study. ${ }^{\prime}$ For several reasons we suspect that they might have made a type II statistical error.
Firstly, there was insufficient separation between the groups in the putative key causal variable. Although the manipulation of the groups was done on the basis of treatment schedule, the authors make repeated reference to only one causal variable, severe hypoglycaemia. The mean number of episodes per patient per year was $1 \cdot 1$ in the intensified treatment group and 0.4 in the standard treatment group. Further, 29(56\%) of the standard treatment group had one or more episodes of severe hypoglycaemia during the study compared with $34(77 \%)$ of the intensified treatment group

Secondly, the statistical power of the study was not high. The power of detecting a difference of 0.5 standard deviation between the two groups was about 0.67 , and the power of detecting a difference of 0.3 standard deviation was only 0.30

Thirdly, their battery of neuropsychological tests contained some of doubtful sensitivity. The authors claim that their tests were well suited to detecting cognitive deterioration and that some of the tests had proved sensitive to acute hypoglycaemia (their references 28-30). What these references show is that tapping and digit span tests were likely to be insensitive to any effects of hypoglycaemia on the brain. The Necker cube test is unknown to most neuropsychologists, and the peculiar results of the 1959 paper that were used to support its inclusion in the battery of tests baffled even the original authors. ${ }^{2}$ The gross brain damage to which this test seemed to be sensitive in the authors' supporting reference bears no comparison with the subtle deficits that may be expected after exposure to severe hypoglycaemia.

Fourthly, five years is too short to afford a clear udgment about the effects of insulin treatment on cognitive functions.

Finally, few contrary positive results were discussed. Using retrospective reports of experience of hypoglycaemia, Langan et al showed a significant correlation between a decrease in IQ from premorbid levels and reported severe hypoglycaemia in 100 insulin treated diabetic patients." The mantra of "prospective good, retrospective bad" should not lead to this result being dismissed. The retrospective reports proved valid and highly reliable. ${ }^{+}$The reports covered a mean of over 10 years, and patients were tested with an extensive battery of cognitive tests, including Wechsler's adult intelligence scale (revised)

Thus the negative result reported by Reichard and colleagues might constitute a type II error. This important issue has not been settled definitively, and we recommend caution to those who might be tempted to believe that repeated severe hypoglycaemia does not have detrimental cognitive effects.

IAN J DEAR

Department of Psycholog

University of Edinburgh

Edinburgh EH8 9JZ

Department of Diabetes,

Royal Infirmary of Edinburgh,

Edinburgh $\mathrm{EH} 39 \mathrm{YW}$

BRIAN M FRIER

Reichard P, Britz A, Rosenqvist U. Intensified conventionat insulin treatment and neuropsychological impairment. $B M \mathcal{J}$ 1991;303:1439-42. (7 December.)

2 Cohen L. Perceptions of reversible figures after brain injury. Archives of Neurology and Psychiatry 1959;81:765-75.

3 Langan SJ, Deary IJ, Hepburn D, Frier BM. Cumulative cognitive impairment following recurrent severe hypoglycaemia in adult patients with insulin-treated diabetes mellitus. Diabetologia 1991;34:337-4

4 Deary IJ, Langan SJ, Graham K, Hepburn D, Frier BM. Recurrent severe hypoglycaemia, intelligence and speed of information processing. Intelligence (in press).

AUTHOR'S REPLY,-A statistical type II error is always possible in a study like ours unless the number of subjects is very large, but for several reasons we think it not very probable.

Firstly, the separation between the groups was such that the number of serious hypoglycaemic episodes per patient was almost three times higher in the intensified treatment group. Our prime aim was to study the effects and side effects of an intensified treatment programme, not to see whether any number of serious hypoglycaemic episodes was harmful to the brain. We found that the improvement in the metabolic control achieved led to a retardation of diabetic microvascular complications. ${ }^{1}$ This treatment, with the increased frequency of hypoglycaemic episodes observed, did not lead to cognitive deficits. This does not mean that serious hypoglycaemia, especially if accompanied by unconsciousness, never causes brain damage. It does cause such damage in rats, but only when the electroencephalogram is isoelectric.

Secondly, the statistical power of our study was such that we ran some risk of statistical type II errors if we used only one or two tests on only one occasion. We used several tests, and some had previously been used after three years' study. ${ }^{3}$ There were no differences between the groups with regard to the results from any test at any time.

Thirdly, the sensitivity of our tests varied, and the most sensitive were probably the trail making test, the perceptual maze test, and the reaction time test with auditory inhibition. The Necker cube test should be seen only as a complement to other tests to determine whether a tendency towards frontal lobe damage concerns unilateral or bilateral changes.

Fourthly, five years of intensified treatment did not lead to any detectable cognitive deficit. Of course a longer period might be necessary, and we will follow up our patients for 10 years altogether.

Finally, to study changes over time you must perform prospective studies. Langan et al's study was retrospective, and the authors can never exclude selection bias. Determining premorbid status retrospectively is associated with a great risk of errors.

In the Stockholm diabetes intervention study intensified insulin treatment led to a retardation of complications. The increased frequency of hypoglycaemic episodes (mostly without coma) did not cause any detectable brain damage. Frequent or prolonged hypoglycaemic unconsciousness might have detrimental long term effects and is also immediately dangerous and unpleasant. It should be avoided.

PER REICHARD

Department of Internal Medicine,

Söderjukhuset,

11883 Stockhom

Sweden

1 Reichard P, Berglund B, Britz A, Cars I, Nilsson BY, Rosenqvist U. Intensified conventional insulin treatment retards the microvascular complications in insulin dependent diabetes mellitus (IDDM): the Stockholm diabetes intervention study (SDIS) after 5 years. $\mathcal{F}$ Intern Med 1991;230:101-8.

2 Auer RN, Olsson Y, Siesjö B. Hypoglycemic brain injury in the rat. Correlation of density of brain damage with the EEG isoelectric time: a quantitative study. Diabetes 1984:33:1090-8. 3 Reichard P, Berglund B, Britz A, Levander S, Rosenqvist U. Hypoglycemic episodes during intensified insulin treatment: increased frequency but no effect on cognitive function. F Intern Med 1991;229:9-16.

\section{Intravenous magnesium in suspected acute myocardial infarction}

SIR, - K K Teo and colleagues describe the possible beneficial effects of intravenous magnesium in acute myocardial infarction.' Magnesium remains an enigmatic treatment. It has been used empirically to treat arrhythmias and began to be used for acute myocardial infarction comparatively recently. Nevertheless, no guidelines exist regarding the salt that should be used, the dose, the infusion times, and the duration of treatment. This is reflected in the different treatment schedules in the overview. At a practical level in different 